\title{
Evaluation of the Pharmacokinetics and Renal Excretion of Simeprevir in Subjects with Renal Impairment
}

\author{
Sivi Ouwerkerk-Mahadevan ${ }^{1} \cdot$ Maria Beumont-Mauviel $^{2} \cdot$ Steven $_{\text {Mortier }^{2}}$. \\ Monika Peeters $^{2} \cdot$ Rene Verloes $^{2} \cdot$ Carla Truyers $^{3,4} \cdot$ Geert Mannens $^{1} \cdot$ \\ Inneke Wynant $^{1} \cdot$ Alexandru Simion ${ }^{2}$
}

Published online: 7 August 2015

(c) The Author(s) 2015. This article is published with open access at Springerlink.com

\begin{abstract}
Background Simeprevir is a N3/4 protease inhibitor approved for the treatment of hepatitis $\mathrm{C}$ virus (HCV) infection. HCV prevalence is higher in patients with chronic kidney disease compared with the general population; safe and efficacious therapies in renal impairment are needed. Objectives To evaluate simeprevir renal excretion in healthy subjects and to compare the simeprevir steady-state pharmacokinetics between subjects with severe renal impairment and healthy subjects.

Methods In the mass balance study, healthy adults received a single 200-mg dose of ${ }^{14} \mathrm{C}$-simeprevir; radioactivity in the urine and feces was quantified until concentrations were $<2 \%$ of the administered dose and seven or more stools were produced. In the pharmacokinetic study, non-HCV-infected adults with severe renal impairment (estimated glomerular filtration rate $\leq 29 \mathrm{~mL} /$ $\min / 1.73 \mathrm{~m}^{2}$ ) and matched healthy subjects (estimated glomerular filtration rate $\geq 80 \mathrm{~mL} / \mathrm{min} / 1.73 \mathrm{~m}^{2}$ ) received $150 \mathrm{mg}$ simeprevir for 7 days. Pharmacokinetic analysis was performed post-dose on Day 7.

Results ${ }^{14} \mathrm{C}$-simeprevir recovery from the urine was low $(0.009-0.138 \%$ of total dose). The minimum plasma concentration, maximum plasma concentration, and area under the plasma concentration-time curve at $24 \mathrm{~h}$ were 71 ,
\end{abstract}

Sivi Ouwerkerk-Mahadevan

SOUWERKE@its.jnj.com

1 Janssen Research \& Development, Turnhoutseweg 30, Beerse 2340, Belgium

2 Janssen Infectious Diseases, Beerse, Belgium

3 Consultant at Janssen Infectious Diseases, Beerse, Belgium

4 Academic Center for General Practice, KU Leuven, Leuven, Belgium
34 , and $62 \%$ higher, respectively, in subjects with severe renal impairment compared with healthy subjects. The mean fraction of simeprevir unbound to protein was $<0.0001$ (all subjects). Most adverse events were grade I or II; one subject with renal impairment who was receiving fenofibrate presented with grade 3 rhabdomyolysis.

Conclusions Simeprevir plasma concentrations were mildly elevated in subjects with severe renal impairment. The results suggest that simeprevir may be administered without dose adjustment in patients with renal impairment.

\section{Key points}

Simeprevir concentrations were mildly elevated in subjects with severe renal impairment.

Simeprevir may be administered without dose adjustment in patients with renal impairment.

\section{Introduction}

Hepatitis C virus (HCV) infection is estimated to affect approximately $3 \%$ of the global population, or more than 170 million people worldwide $[1,2]$. The prevalence of $\mathrm{HCV}$ is higher in patients with chronic kidney disease (CKD), with reported prevalence rates ranging from 3 to $68 \%$ (region- and dialysis center-dependent) in patients receiving hemodialysis [3, 4], and between 10 and $49 \%$ in renal transplant recipients [5]. Epidemiology studies in patients with CKD prior to dialysis or renal transplant are limited; however, the prevalence of HCV is likely also increased in this population $[1,6]$. 
Two main factors contribute to the association between $\mathrm{HCV}$ and renal disease. First, $\mathrm{HCV}$ has been associated with the development of glomerular renal disease, most commonly membranoproliferative glomerulonephritis (with or without essential mixed cryoglobulinemia) and membranous glomerulonephritis [7]. Second, patients with CKD have an increased risk of exposure to HCV, with the potential for infection via blood transfusions (prior to standardized screening procedures), nosocomial transmission during dialysis, and renal transplantation [1, 7].

Increased morbidity and mortality and reduced longterm graft survival in transplant recipients have been demonstrated in patients with CKD with coexisting HCV infection [8, 9]. Therefore, the Kidney Disease Improving Global Outcomes guidelines suggest that all patients with CKD and HCV infection be evaluated for antiviral treatment [1]; however, treatment of $\mathrm{HCV}$ in patients with severe renal dysfunction can be challenging [10]. Renal catabolism and filtration are important in the clearance of both ribavirin and interferon [11], resulting in increased exposure to both agents in severe renal impairment [12-14]. Increased exposure may lead to reduced tolerance [higher dropout rates have been reported in subjects with end-stage renal disease (ESRD) treated with pegylated interferon] and an increased risk of ribavirin-associated hemolytic anemia, which is proportional to plasma concentration $[15,16]$. As a result, dosing adjustment is required in patients with a creatinine clearance $(\mathrm{CrCl})$ of $\leq 50 \mathrm{~mL} / \mathrm{min}$ for ribavirin and pegylated interferon alfa- $2 \mathrm{~b}$ and $\mathrm{a} \mathrm{CrCl}$ of $<30 \mathrm{~mL} / \mathrm{min}$ for pegylated interferon alfa-2a [13, 17-19]. Sustained virologic response (SVR) rates to interferon monotherapy are increased in patients with CKD (ESRD on hemodialysis) compared with patients with normal renal function, likely secondary to increased exposure; however, they are lower than those reported for interferon and ribavirin combination therapy, which is often avoided in subjects with severe renal impairment [1, 20-22]. Sofosbuvir, a nucleotide NS5B polymerase inhibitor, is primarily eliminated in the urine, and increased exposure in renal failure has been reported; the sofosbuvir package insert states that a dosing recommendation cannot be made for patients with severe renal impairment or ESRD [23].

In contrast, boceprevir and telaprevir, the first-generation NS3/4A protease inhibitors, are metabolized and excreted by the liver, and pharmacokinetic studies have demonstrated similar exposure in subjects with renal impairment compared with healthy subjects [24, 25]. In addition, the NS5A replication complex inhibitor daclatasvir is also primarily excreted in the feces $(<10 \%$ renal excretion); although mildly increased daclatasvir exposures have been observed with renal impairment, daclatasvir may be administered for all degrees of renal impairment without dose adjustment [26, 27].
Simeprevir is a once-daily oral HCV N3S/4A protease inhibitor for the treatment of chronic $\mathrm{HCV}$ genotype 1 infection as a component of combination antiviral therapy $[28,29]$. Combination therapy with simeprevir has demonstrated high SVR rates in both phase II and III trials for patients with $\mathrm{HCV}$ genotype 1 with normal renal function [29-34]. In treatment-naïve patients, the phase III QUEST-1 and QUEST-2 trials demonstrated SVR rates of 80 and $81 \%$, respectively, in subjects receiving simeprevir plus ribavirin and pegylated interferon, compared with a SVR rate of $50 \%$ in subjects receiving pegylated interferon and ribavirin alone $[33,34]$. In prior relapser patients, the phase III PROMISE trial demonstrated an SVR rate of $79.2 \%$ in subjects receiving simeprevir, pegylated interferon, and ribavirin, compared with an SVR rate of $36.1 \%$ in subjects receiving pegylated interferon and ribavirin alone [31]. Even higher SVR rates of 92-94\% were observed using combination therapy with simeprevir plus sofosbuvir with or without ribavirin in the phase II COSMOS trial [35]. Phase III trials have also demonstrated the efficacy of simeprevir in patients with human immunodeficiency virus (HIV) coinfection and in patients with genotype 4 (simeprevir is approved for the treatment of genotype 4 in Europe and Australia) [36, 37].

The safety of simeprevir has been demonstrated in subjects without renal impairment in both phase II and III trials [28, 33-35]. In pooled results from the three phase III trials evaluating simeprevir in combination with pegylated interferon and ribavirin (QUEST-1, QUEST-2, and PROMISE), similar rates of grade 3 and 4 adverse events (AEs) were observed with simeprevir combination therapy compared with pegylated interferon and ribavirin alone [28, 33, 34]. In addition, the phase II COSMOS trial that evaluated simeprevir in combination with sofosbuvir demonstrated a $<5 \%$ rate of grade 3 and 4 AEs, excluding increased blood amylase levels [35].

Here, we report the results of two phase I, open-label studies of simeprevir relevant to the safety of simeprevir in subjects with renal impairment. Study 1, the mass balance study, characterizes the excretion of ${ }^{14} \mathrm{C}$-simeprevir in healthy subjects. Study 2 evaluates the steady-state pharmacokinetics and short-term safety and tolerability of simeprevir in non-HCV-infected subjects with severe renal impairment in comparison with healthy subjects.

\section{Materials and Methods}

\subsection{Study 1: ${ }^{14} \mathrm{C}-$ Simeprevir Mass Balance Study}

\subsubsection{Subjects}

Eligible subjects included healthy male individuals between 18 and 55 years of age with a body mass index 
(BMI) between 18.0 and $30.0 \mathrm{~kg} / \mathrm{m}^{2}$, a normal screening electrocardiogram, and a history of nonsmoking for at least 3 months prior to enrollment. Pre-study health was based on medical history and pre-study physical examination, vital signs, and blood (biochemistry and hematology) and urine laboratory evaluations. Key exclusion criteria included: a history of hepatitis A, B, or C or HIV infection; active or underlying disease (including gastrointestinal, cardiovascular, nervous system, psychiatric, renal, hepatic, metabolic, respiratory, inflammatory, or infectious disease); a history of clinically significant cardiac arrhythmia; several episodes of constipation (less than one stool every 3 days) or diarrhea (three or more stools per day) during the previous 2 months; and the use of medications (except for paracetamol or ibuprofen) within 14 days of study medication intake.

\subsubsection{Study Design}

All subjects received a single 200-mg dose of the oral formulation of simeprevir containing ${ }^{14} \mathrm{C}$-labeled and unlabeled simeprevir in polyethylene glycol 400 on study Day 1 in the fed condition; the total radioactivity dose was $1.85 \mathrm{MBq}$ (equivalent to $50 \mu \mathrm{Ci}$ ). Urine and feces were collected until at least Day 8 and until the radioactivity in the urine and feces combined was $<2 \%$ of the administered dose (over a period of $24 \mathrm{~h}$ ) and the subject produced at least seven stools. Urine was collected during the following intervals following dose administration: $0-8,8-16,16-24,24-36$, and 36-48 h; after $48 \mathrm{~h}$, urine was collected every $24 \mathrm{~h}$. All fecal output was collected (per stool). Total radioactivity was measured in the urine and feces using liquid scintigraphy; the lower limit of quantification was 0.002-0.093\% for urine and $0.027-0.185 \%$ for feces. Safety evaluation included subject-reported AEs, laboratory analysis (hematology, biochemistry, and coagulation), urinalysis, and electrocardiogram.

\subsubsection{Statistical Analysis}

The primary study endpoint was the total excretion of simeprevir-related radioactivity in the urine and feces. With a percentage coefficient of variation of approximately $30 \%$, six subjects were included. Subjects who received the single dose of the study medication were included in the analysis (intention-to-treat population). The percentage of simeprevir-related radioactivity of the total administered dose was determined for urine and feces. Descriptive statistics were used for demographic characteristics and total radioactivity levels.

\subsection{Study 2: Simeprevir in Subjects with Severe Renal Impairment}

\subsubsection{Subjects}

Eligible subjects included non-HCV-infected male and post-menopausal or non-pregnant, non-lactating female subjects between 18 and 70 years of age with a BMI of $18-35 \mathrm{~kg} / \mathrm{m}^{2}$ and a history of light or nonsmoking for 3 months prior to screening ( $\leq 10$ cigarettes or two cigars or pipes per day). Subjects in the severe renal impairment group were required to have an estimated glomerular filtration rate $(\mathrm{eGFR})$ of $\leq 29 \mathrm{~mL} / \mathrm{min} / 1.73 \mathrm{~m}^{2}$ (determined by the Modification of Diet in Renal Disease equation), stable renal disease (plasma creatinine within $25 \%$ of the last value obtained within 6 months of the study) and treatment regimen (from 2 months prior to study initiation); subjects could not be receiving dialysis or be expected to receive dialysis within the next 3 months. Subjects with diabetes mellitus were eligible, provided that the disease was controlled (defined as glycosylated hemoglobin $<7 \%$ ). Control subjects had to be healthy based on medical history and pre-study physical examination, vital signs, electrocardiogram, and blood (biochemistry, hematology, coagulation) and urine laboratory evaluations (conducted at screening). They were also required to have normal renal function, defined as an eGFR of $\geq 80 \mathrm{~mL} /$ $\min / 1.73 \mathrm{~m}^{2}$ (determined by the Modification of Diet in Renal Disease equation), and be matched to a subject with severe renal impairment in sex, race, age (within 10 years), and BMI (within $20 \%$ ).

Subjects in both groups were excluded for a history of hepatitis A, B, or C or HIV infection. Subjects in the severe renal impairment group were also excluded for a history of renal carcinoma (unless cancer free for $\geq 5$ years) or transplant, hepatorenal syndrome, uncontrolled hypertension, the use of disallowed medications (statins), or other significant diseases. Healthy subjects were also excluded for a history of congenital or hereditary kidney disease, nephrectomy, renal transplant, nephrolithiasis, or the use of medications other than paracetamol or ibuprofen.

\subsubsection{Study Design}

All subjects received a 150-mg oral dose (capsule) of simeprevir daily in the fed condition for 7 days. Pharmacokinetic analysis began on Day 7 following a $\geq 10$-h fast and a standardized breakfast. Venous blood sampling for simeprevir plasma concentrations was performed on Days 5, 6, and 7; full pharmacokinetic profiling was performed on Day 7. Samples were drawn pre-dose on Days 5 and 6 and pre-dose and at 0.5, 1, 1.5, 2, 3, 4, 6, 9, 12, 16, 24, 48, 
and $72 \mathrm{~h}$ post-dose on Day 7. Simeprevir plasma concentrations were determined using liquid chromatographymass spectrometry/mass spectrometry. Unbound simeprevir concentrations were determined from blood samples drawn pre-dose and $4 \mathrm{~h}$ post-dose using liquid scintillation counting of fortified ${ }^{3} \mathrm{H}$-simeprevir after dialysis. Safety evaluation included subject-reported AEs, laboratory analysis (hematology and biochemistry on Days 1, 3, 5, 7, and 8), urinalysis (Days 1 and 7), and electrocardiograms (Days 1 and 7).

\subsubsection{Statistical Analysis}

The primary endpoint was comparison of steady-state pharmacokinetics of simeprevir between subjects with severe renal impairment and matched subjects with normal renal function. The secondary endpoint was short-term safety and tolerability. No formal sample size determination was performed; a sample size of eight subjects per group was considered sufficient for pharmacokinetic assessment. Subjects who received at least one dose of the study medication were included in the analysis (intentionto-treat population). Noncompartmental pharmacokinetic analysis was conducted with WinNonlin Professional ${ }^{\mathrm{TM}}$ version 4.1 (Pharsight Corporation, Mountain View, CA, USA). Descriptive statistics (mean, standard deviation [SD]) were calculated for total and unbound plasma concentrations at each time point. For the full pharmacokinetic profile, the minimum plasma concentration $\left(C_{\min }\right)$, maximum plasma concentration $\left(C_{\max }\right)$, and area under the plasma concentration-time curve at $24 \mathrm{~h}\left(\mathrm{AUC}_{24}\right)$ on the logarithmic scale were the primary pharmacokinetic parameters of interest. A linear mixed-effects model (controlling for renal function) was used to estimate the least-squares (LS) means for each of the parameters. A $90 \%$ confidence interval (CI) was created around the difference between the LS means in the renal impairment and control groups. The Wilcoxon rank sum test was used for the comparison of the time to maximal plasma concentration $\left(T_{\max }\right)$ between groups. No formal hypothesis testing was performed.

\section{Results}

\subsection{Study 1: ${ }^{14} \mathrm{C}-$-Simeprevir Mass Balance Study}

Six male subjects were enrolled between February 2008 and April 2008; all subjects completed the study. Baseline demographics are shown in Table 1. Subjects were male, Caucasian, and nonsmoking. The median age was 47.0 years.
The mean total recovery of simeprevir-related radioactivity from the urine and feces combined was $91.18 \%$ [standard deviation (SD), 16.00]. The total simeprevirrelated radioactivity recovered from the urine was low and ranged between 0.009 and $0.138 \%$ of the total radioactive dose (Table 2). Of the radioactivity excreted in the urine, the majority was excreted within 16-24 h post-dose. The majority of the radioactivity was excreted in the feces, ranging between 59 and $101 \%$ (101\% because of rounding in one subject with a recovery slightly $>100 \%$ ) of the total radioactive dose. One of the six subjects had a low radioactivity recovery of $59 \%$ from the feces (reasons unclear); however, recovery in the remaining subjects was 93-100\%. The largest fraction of radioactivity was excreted in the feces within 3 and 4 days post-dose (Fig. 1).

For the study period (including screening, treatment period, and follow-up), at least one $\mathrm{AE}$ was reported in five subjects; these included increased alanine aminotransferase (ALT) and aspartate aminotransferase (AST) levels (two subjects), prolonged activated partial thromboplastin time (aPTT; two subjects), and dry mouth (one subject). Two AEs (both prolonged aPTT) were considered by the investigator to be very likely related to simeprevir, and four AEs (increased AST and ALT) were considered by the investigator to be possibly related to simeprevir. No deaths or AEs resulting in permanent premature discontinuation from the study occurred.

\subsection{Study 2: Simeprevir in Subjects with Severe Renal Impairment}

Sixteen subjects, eight subjects with severe renal impairment and eight matched healthy subjects were enrolled between August 2011 and December 2011; all subjects completed the study. Baseline and demographic data are shown in Table 1. A majority of subjects were male and Caucasian. The median age was similar among groups; 55.0 years (range 36-67 years) for subjects with renal impairment and 57.0 years (range 37-61 years) for control subjects. The median (range) eGFR was $19.9 \mathrm{~mL} / \mathrm{min} /$ $1.73 \mathrm{~m}^{2}$ (range $12-28 \mathrm{~mL} / \mathrm{min} / 1.73 \mathrm{~m}^{2}$ ) in the renal impairment group and $94.4 \mathrm{~mL} / \mathrm{min} / 1.73 \mathrm{~m}^{2}$ (range $84-110 \mathrm{~mL} / \mathrm{min} / 1.73 \mathrm{~m}^{2}$ ) in the control group.

Steady-state pharmacokinetics were reached prior to blood sampling on Day 7 for most subjects, although concentrations increased after Day 7 for some subjects in both groups. Mean plasma concentrations were higher for subjects in the renal impairment group when compared with subjects in the control group on all measured study days (Table 3). Pharmacokinetic analysis on Day 7 revealed no major differences in the shape of the 
Table 1 Subject demographics

\begin{tabular}{|c|c|c|c|}
\hline \multirow[t]{2}{*}{ Characteristic } & \multirow{2}{*}{$\begin{array}{l}\text { Study } 1 \\
\text { All subjects }(n=6)\end{array}$} & \multicolumn{2}{|l|}{ Study 2} \\
\hline & & Renally impaired subjects $(n=8)$ & Healthy controls $(n=8)$ \\
\hline Median (range) eGFR $\left(\mathrm{mL} / \mathrm{min} / 1.73 \mathrm{~m}^{2}\right)$ & NA & $19.9(12-28)$ & $94.4(84-110)$ \\
\hline Median (range) age (years) & $47.0(35.0-51.0)$ & $55.0(36-67)$ & $57.0(37-61)$ \\
\hline \multicolumn{4}{|l|}{ Sex, $n(\%)$} \\
\hline Male & $6(100)$ & $7(87.5)$ & $7(87.5)$ \\
\hline Female & 0 & $1(12.5)$ & $1(12.5)$ \\
\hline \multicolumn{4}{|l|}{ Race } \\
\hline Caucasian & $6(100)$ & $8(100)$ & $8(100)$ \\
\hline Median (range) BMI $\left(\mathrm{kg} / \mathrm{m}^{2}\right)$ & $23.9(20.7-27.4)$ & $27.8(24-32)$ & $25.7(23-29)$ \\
\hline Median (range) height $(\mathrm{cm})$ & $171.5(162.0-184.0)$ & $173.0(161-187)$ & $177(161-186)$ \\
\hline Median (range) weight (kg) & $70.0(61.0-81.0)$ & $83.5(67-100)$ & $81.5(68-93)$ \\
\hline \multicolumn{4}{|l|}{ Type of smoker, $n(\%)$} \\
\hline Light/nonsmoker & $6(100)$ & $8(100)$ & $8(100)$ \\
\hline
\end{tabular}

$B M I$ body mass index, $e G F R$ estimated glomerular filtration rate, $N A$ not available

Table 2 Percentage of total radioactivity dose recovered in the urine and feces for individual subjects

\begin{tabular}{|c|c|c|c|c|c|c|}
\hline \multirow[t]{2}{*}{ Collection interval (h) } & \multicolumn{6}{|c|}{ Total radioactivity in urine $(\%)^{\mathrm{a}}$} \\
\hline & Subject 1 & Subject 2 & Subject 3 & Subject 4 & Subject 5 & Subject 6 \\
\hline $0-8$ & 0 & 0 & 0 & 0 & 0 & 0 \\
\hline $8-16$ & 0 & 0 & 0.029 & 0 & 0 & 0 \\
\hline $16-24$ & 0.019 & 0.009 & 0.058 & 0.019 & 0.010 & 0.022 \\
\hline $24-36$ & 0.015 & 0 & 0.021 & 0 & 0 & 0 \\
\hline $36-48$ & 0 & 0 & 0.030 & 0 & 0 & 0 \\
\hline Total & 0.034 & 0.009 & 0.138 & 0.019 & 0.010 & 0.022 \\
\hline \multirow[t]{2}{*}{ Collection interval (h) } & \multicolumn{6}{|c|}{ Total radioactivity in feces $(\%)$} \\
\hline & Subject 1 & Subject 2 & Subject 3 & Subject 4 & Subject 5 & Subject 6 \\
\hline \multicolumn{7}{|c|}{$\begin{array}{l}\text { Not quantifiable radioactivity was detected in the urine from } 48 \text { to } 216 \mathrm{~h} \text { of collection in any subject } \\
\text { b Subject } 6 \text { had a recovery slightly }>100 \% \text {, which rounded to } 101 \%\end{array}$} \\
\hline
\end{tabular}

plasma concentration-time curve between groups (Fig. 2). Based on the LS mean ratio, the key pharmacokinetic parameters $C_{\min }, C_{\max }$, and $\mathrm{AUC}_{24 \mathrm{~h}}$ of simeprevir were approximately 71,34 , and $62 \%$ higher, respectively, in subjects with severe renal impairment compared with matched healthy subjects (Table 4). Scatter plots (not shown) demonstrated no correlation between individual eGFR values and individual $C_{\max }$ and $\mathrm{AUC}_{24 \mathrm{~h}}$ values.

The median $T_{\max }$ was $6 \mathrm{~h}$ (range $4-9 \mathrm{~h}$ ) in both groups. Simeprevir plasma concentration declined more slowly in subjects with renal impairment compared with healthy subjects (Fig. 3). In addition, the mean half-life was prolonged in subjects with renal impairment, which was $24 \mathrm{~h}$ compared with $16.7 \mathrm{~h}$ in healthy subjects.
The mean unbound plasma concentrations in subjects with renal impairment were 0.2892 (SD 0.4411) at pre-dose and 0.4216 (SD 0.3319) at $4 \mathrm{~h}$, which were higher compared with matched healthy subjects: (mean 0.1142, SD 0.1567 at pre-dose, and mean 0.2714 , SD 0.2574 at $4 \mathrm{~h}$ ). The mean fraction of simeprevir unbound to protein (fu) was about 0.0001 in both groups.

For the study period (including screening, treatment period, and follow-up), at least one $\mathrm{AE}$ was reported in four subjects $(50 \%)$ in the renal impairment group and three subjects $(37.5 \%)$ in the control group (Table 5). During the treatment phase, four subjects $(50 \%)$ in the renal impairment group had at least one AE compared with one subject $(12.5 \%)$ in the control group. Most AEs were grade 1 or 2 in severity; a grade 3 rhabdomyolysis was 


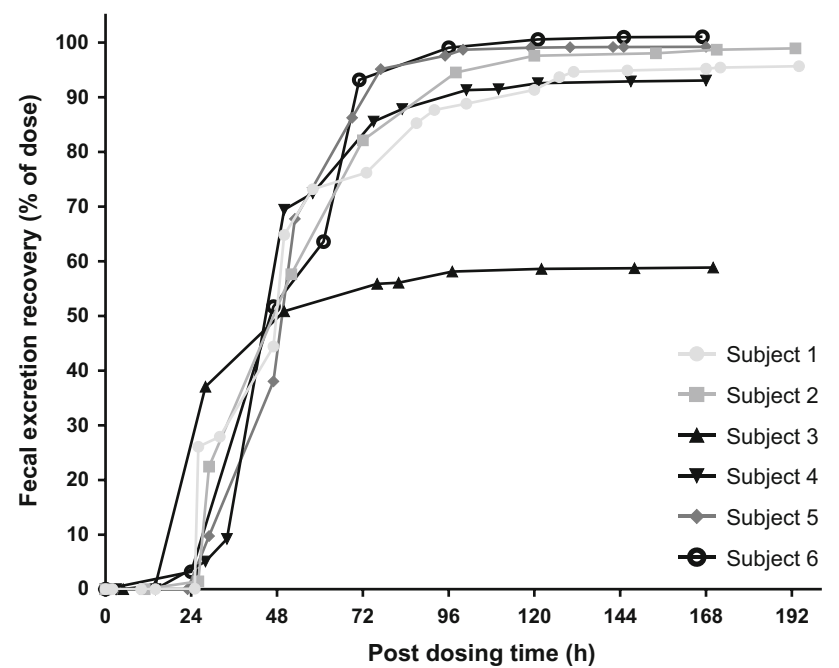

Fig. 1 Cumulative excretion of the radioactivity in feces as a function of time after a single oral administration of $200 \mathrm{mg}$ of ${ }^{14} \mathrm{C}$-simeprevir

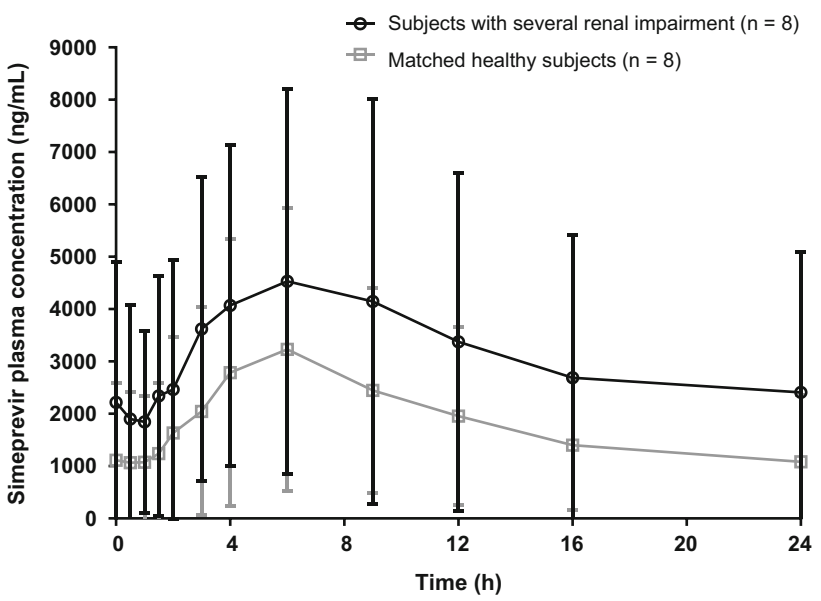

Fig. 2 Linear plasma concentration-time profiles of simeprevir in subjects with several renal impairment and controls

Table 3 Pharmacokinetics of simeprevir in subjects with severe renal impairment and healthy matched controls

\begin{tabular}{lcr}
\hline Pharmacokinetic parameters mean $(\mathrm{SD})$ & Renally impaired subjects $(n=8)$ & Matched healthy controls $(n=8)$ \\
\hline Day 5 & $1688(1882)$ & $825.1(1004)$ \\
$\quad C_{0 \mathrm{~h}}(\mathrm{ng} / \mathrm{mL})$ & $1944(2254)$ & $939.0(1142)$ \\
Day 6 & & $1112(1480)$ \\
$C_{0 \mathrm{~h}}$ & $2220(2696)$ & $961.3(1191)$ \\
Day 7 & $1707(1741)$ & $3378(2636)$ \\
$C_{0 \mathrm{~h}}(\mathrm{ng} / \mathrm{mL})$ & $4671(3823)$ & $6.0(4.0-9.0)$ \\
$C_{\min }(\mathrm{ng} / \mathrm{mL})$ & $6.0(4.0-9.0)$ & $44,380(39,920)$ \\
$C_{\max }(\mathrm{ng} / \mathrm{mL})$ & $76,690(71,740)$ & \\
$T_{\max }(\mathrm{h})^{\mathrm{a}}$ & & \\
$\mathrm{AUC}$ &
\end{tabular}

$A U C_{24 h}$ area under the plasma concentration-time curve for $24 \mathrm{~h}$ post-dose, $C_{O h}$ predose plasma concentration, $C_{\max }$ maximum plasma concentration, $C_{\min }$ minimum plasma concentration, $S D$ standard deviation, $T_{\max }$ time to reach $C_{\max }$

${ }^{\text {a }}$ Values presented are the median (range)

observed in the renal impairment group. AEs during the treatment phase in the renal impairment group included: myalgia, rhabdomyolysis, hypertension, hyperbilirubinemia, and increased blood alkaline phosphatase; all were experienced by one subject $(12.5 \%)$ each. Hyperbilirubinemia was the only AE observed during the treatment phase in the control group. No deaths or AEs resulting in permanent premature discontinuation of simeprevir occurred. All AEs were considered by the investigator to be unrelated or doubtfully related to simeprevir, aside from rhabdomyolysis and myalgia, which were considered probably related to simeprevir. These were experienced by the same subject who was also taking high-dose fenofibrate. This subject experienced myalgia on Day 4 (recovered 1 day later) and elevated AST, ALT, lactate dehydrogenase, and bilirubin (direct and indirect) levels on Day 8; rhabdomyolysis was confirmed on Day 9 with a creatine kinase level of $96.76 \mu \mathrm{kat} / \mathrm{L}$, creatine kinase muscle brain fraction levels of 20.84 and $19.45 \mu \mathrm{g} / \mathrm{L}$, and myoglobin levels of 1200,1475 , and $1476 \mu \mathrm{g} / \mathrm{L}$ on Day 9 . The subject was hospitalized for 3 days and received ademetionine; laboratory values gradually decreased over the following 30 days.

\section{Discussion}

Given the increased prevalence of HCV in patients with $\mathrm{CKD}$ and the increased morbidity and mortality associated with $\mathrm{HCV}$ in this population, $\mathrm{HCV}$ therapies that are safe 
Table 4 Statistical evaluation of simeprevir pharmacokinetics

\begin{tabular}{|c|c|c|c|c|}
\hline \multirow[t]{2}{*}{ Parameter } & \multicolumn{2}{|l|}{ LS means } & \multirow[t]{2}{*}{ LS means ratio } & \multirow[t]{2}{*}{$90 \% \mathrm{CI}$} \\
\hline & Renally impaired subjects $(n=8)$ & Matched healthy controls $(n=8)$ & & \\
\hline$C_{\min }(\mathrm{ng} / \mathrm{mL})$ & 985.5 & 577.5 & 1.71 & $0.65,2.50$ \\
\hline$C_{\max }(\mathrm{ng} / \mathrm{mL})$ & 2588 & 3459 & 1.34 & $0.66,2.72$ \\
\hline $\mathrm{AUC}_{24 \mathrm{~h}},(\mathrm{ng} \cdot \mathrm{h} / \mathrm{mL})$ & 32,010 & 51,710 & 1.62 & $0.73,3.59$ \\
\hline$T_{\max }(\mathrm{h})$ & $6.0(4.0-9.0)^{\mathrm{a}}$ & $6.0(4.0-9.0)^{\mathrm{a}}$ & 0.0 & $0.0,0.2$ \\
\hline
\end{tabular}

$A U C_{24 h}$ area under the plasma concentration-time curve for $24 \mathrm{~h}$ post-dose, $C I$ confidence interval, $C_{\max }$ maximum plasma concentration, $C_{\text {min }}$ minimum plasma concentration, $L S$ least squares, $T_{\max }$ time to reach $\mathrm{C}_{\max }$

${ }^{a}$ Values presented are the median (range)

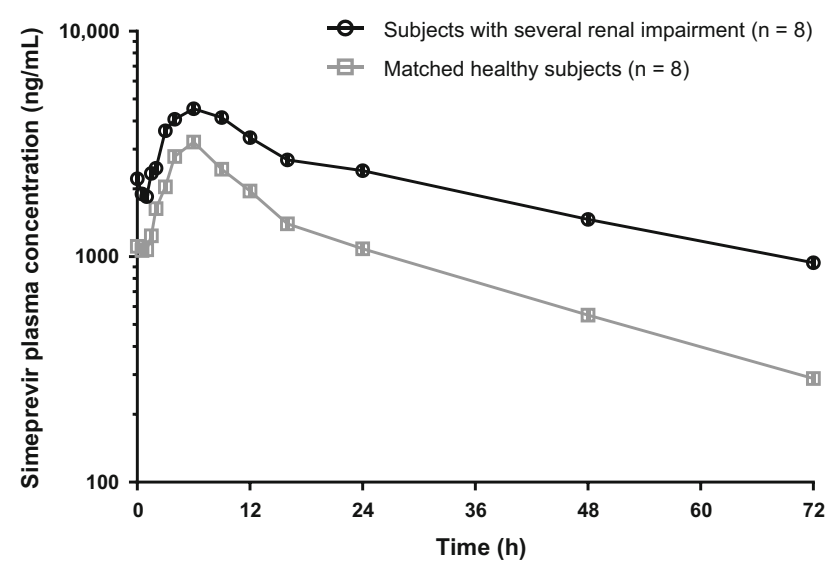

Fig. 3 Semilogarithmic plasma concentration-time profiles of simeprevir in subjects with several renal impairment and controls

and effective in patients with CKD are needed. Simeprevir is a once-daily, oral HCV NS3/4A protease inhibitor for the treatment of chronic HCV genotype 1 infection, as a component of combination antiviral therapy [28, 29]. In phase II and III studies, simeprevir has been demonstrated to be safe, with high SVR rates when used in combination with ribavirin and pegylated interferon or sofosbuvir [2934].

These two studies demonstrated that simeprevir has minimal renal excretion and that its pharmacokinetics are not altered to a clinically significant degree in patients with severe renal impairment, which suggests that simeprevir may be administered without dose adjustment in patients with mild, moderate, or severe renal impairment.

The ${ }^{14} \mathrm{C}$-simeprevir mass balance study demonstrated a predominance of fecal excretion (59-101\%), with $<2 \%$ of ${ }^{14} \mathrm{C}$-simeprevir excreted in the urine. This suggests that simeprevir is primarily eliminated by biliary excretion with insignificant renal clearance. These results are consistent with preclinical studies that demonstrated that simeprevir was predominately distributed to the liver and intestines with low distribution (similar or less than plasma) to the kidneys [38, 39]. These results suggest that renal

Table 5 Incidence of treatment-emergent adverse events

\begin{tabular}{|c|c|c|c|c|c|c|}
\hline \multirow[t]{2}{*}{ Adverse event, $n(\%)$} & \multicolumn{3}{|c|}{ Renally impaired subjects } & \multicolumn{3}{|c|}{ Matched healthy controls } \\
\hline & Treatment phase & Follow-up & Whole study ${ }^{a}$ & Treatment phase & Follow-up & Whole study ${ }^{\mathrm{a}}$ \\
\hline Any AE & $4(50.0)$ & $1(12.5)$ & $4(50.0)$ & $1(12.5)$ & $2(25.0)$ & $3(37.5)$ \\
\hline Hyperbilirubinemia & $1(12.5)$ & 0 & $1(12.5)$ & $1(12.5)$ & $1(12.5)$ & $2(25.0)$ \\
\hline Pneumonia & 0 & $1(12.5)$ & $1(12.5)$ & 0 & 0 & 0 \\
\hline Myalgia & $1(12.5)$ & 0 & $1(12.5)$ & 0 & 0 & 0 \\
\hline Rhabdomyolysis & $1(12.5)$ & 0 & $1(12.5)$ & 0 & 0 & 0 \\
\hline Hypertension & $1(12.5)$ & 0 & $1(12.5)$ & 0 & 0 & 0 \\
\hline \multicolumn{7}{|l|}{ Investigations } \\
\hline Prolonged aPTT & 0 & $1(12.5)$ & $1(12.5)$ & 0 & 0 & 0 \\
\hline Increased blood ALP & $1(12.5)$ & 0 & $1(12.5)$ & 0 & 0 & 0 \\
\hline Increased hepatic enzyme & 0 & 0 & 0 & 0 & $1(12.5)$ & $1(12.5)$ \\
\hline
\end{tabular}

$A E$ adverse event, $A L P$ alkaline phosphatase, $a P T T$ activated partial thromboplastin time

a The whole study periods include screening, treatment phase, and follow-up 
impairment would be unlikely to affect the pharmacokinetics of simeprevir; however, given that severe renal impairment may affect pharmacokinetics through diverse mechanisms, such as alterations in cytochrome P450 activity, conjugation reactions (glucuronidation and acetylation), and intestinal or hepatic transport, a pharmacokinetic study (Study 2) in subjects with severe renal impairment was also performed [40].

Pharmacokinetic studies of simeprevir in subjects with severe renal impairment demonstrated that most subjects with renal impairment reached steady state within 7 days; these results were comparable to subjects without renal impairment in both this study and in previous studies [28]. Slightly higher plasma concentrations of simeprevir were seen in subjects with severe renal impairment compared with healthy subjects with a $C_{\min }, C_{\max }$, and $\mathrm{AUC}_{24 \mathrm{~h}}$ that were approximately 71,34 , and $62 \%$ higher, respectively. The $90 \%$ confidence intervals were wide because of the small sample size and high inter-subject variability. These mild increases in simeprevir plasma concentrations are unlikely to be clinically significant. In addition, the concentrations observed in this study (non-HCV-infected subjects with renal impairment) were within the range of concentrations observed in phase III studies (AUC 4848-449,185 $\mathrm{ng} \cdot \mathrm{h} / \mathrm{mL}$ ) in HCV-infected subjects without renal impairment [41]. It is important to note that subjects with HCV infection have been shown to have two- to threefold higher concentrations when compared with non-HCVinfected subjects and, therefore, simeprevir concentrations in HCV-infected patients with renal impairment would be expected to be higher than those observed in this study [28].

In addition, the mean half-life of simeprevir was prolonged in subjects with severe renal impairment when compared with subjects with normal renal function (24 and $16.7 \mathrm{~h}$, respectively). Similar to simeprevir concentrations, differences in the half-life of simeprevir have also been observed between non-HCV-infected subjects and HCVinfected subjects with normal renal function; the half-life of simeprevir is between 10 and $13 \mathrm{~h}$ in non-HCV-infected subjects and $41 \mathrm{~h}$ in $\mathrm{HCV}$-infected subjects [28]. Therefore, the half-life of simeprevir in HCV-infected subjects with renal impairment may be longer than that reported for non-HCV-infected subjects with renal impairment in this study.

Simeprevir was well tolerated in subjects with renal impairment in this study; the majority of AEs were mild/moderate in severity. All AEs were considered by the investigator to be unrelated or doubtfully related to simeprevir, except for the serious AE rhabdomyolysis and the AE myalgia, which were considered probably related to simeprevir; these were experienced by the same patient who was also taking high-dose fenofibrate, which has been associated with AST and ALT elevations, myopathy, and rhabdomyolysis [42].

The safety and efficacy of simeprevir has not been evaluated in patients with ESRD (eGFR $<15 \mathrm{~mL} / \mathrm{min}$ ), including patients who require dialysis. Simeprevir is highly bound to plasma proteins $(\geq 99 \%)$; therefore, simeprevir would not be expected to be removed by dialysis. Further studies are needed to evaluate the efficacy and safety of simeprevir in patients with ESRD and in patients requiring dialysis. The results obtained in this study are consistent with those seen with other N3/4 protease inhibitors used to treat $\mathrm{HCV}$, such as boceprevir and telaprevir. These agents have similarly demonstrated minimal renal excretion and nonclinically significant pharmacokinetic alterations in subjects with renal impairment $[18,24,25$, 43-45].

The renal system plays an important role in the elimination of other HCV therapies, including ribavirin and pegylated interferon; the pharmacokinetics of these medications demonstrate greater alterations in patients with renal impairment [12, 18, 23]. For ribavirin, a ${ }^{14} \mathrm{C}$-ribavirin excretion study demonstrated that $61 \%$ of radioactivity was excreted in the urine following a $600-\mathrm{mg}{ }^{14} \mathrm{C}$-ribavirin dose [12]. A study comparing the pharmacokinetics of ribavirin between 18 subjects with renal impairment (mild, moderate, or severe) and six healthy subjects demonstrated a decrease in apparent clearance of approximately $50-75 \%$ and a twoto three-fold increase in AUC in subjects with moderate to severe renal impairment following a single 400-mg dose [46]. For interferon- $\alpha_{2 b}$, a single-dose pharmacokinetic study of 20 subjects with renal impairment (all severities) and six healthy control subjects found decreases in apparent clearance of up to $45 \%$ and a $90 \%$ increase in AUC and $C_{\max }$ in subjects with severe renal impairment compared with healthy subjects, following a $1-\mu \mathrm{g} / \mathrm{kg}$ subcutaneous dose [14]. The effects of renal impairment on the pharmacokinetics of interferon- $\alpha_{2 \mathrm{a}}$ may be less pronounced as it is largely metabolized by the liver; the package label reports a 25-45\% reduction in clearance in ESRD on hemodialysis $[13,18]$.

In addition, the renal system is important for the elimination of sofosbuvir, an NS5B protease inhibitor that is recommended in the American Association for the Study of Liver Disease/Infectious Diseases Society of America guidelines (as part of combination therapy) for the treatment of all genotypes in patients with normal renal function who are initiating or who have relapsed following pegylated interferon/ribavirin therapy [19]. The package insert reports that $80 \%$ of ${ }^{14} \mathrm{C}$-sofosbuvir was recovered from the urine following a $400-\mathrm{mg}{ }^{14} \mathrm{C}$-sofosbuvir dose [23]. In addition, pharmacokinetic studies in subjects with renal impairment have demonstrated increases in the area under the curve to infinity ( $\mathrm{AUC}_{\mathrm{inf}}$ ) of 61,107 , and $171 \%$ 
in subjects with mild, moderate, and severe renal impairment, respectively, compared with subjects with normal renal function, following a single 400-mg dose [23]. Because the safety and efficacy of sofosbuvir have not been established in people with severe renal impairment (eGFR $<30 \mathrm{~mL} / \mathrm{min} / 1.73 \mathrm{~m}^{2}$ ), no dose recommendations were given for these individuals [23]. Moreover, the use of simeprevir in combination with sofosbuvir in patients with renal impairment has not been studied.

For daclatasvir, an NS5A replication complex inhibitor, a ${ }^{14} \mathrm{C}$-daclatasvir excretion study demonstrated that only $6.6 \%$ of the total radioactivity dose was eliminated in urine ( $88 \%$ recovery from the feces) [26]. Pharmacokinetic studies have demonstrated only mild increases in the $\mathrm{AUC}_{\text {inf }}$ of approximately 18,39, and $51 \%$ in subjects with moderate, severe, and ESRD, respectively [26, 27]; therefore, daclatasvir may be administered to patients with all degrees of renal impairment and in ESRD without dose adjustment [26].

\section{Conclusions}

Simeprevir plasma concentrations were mildly increased in subjects with severe renal impairment. The results suggest that simeprevir may be administered without dose adjustment in patients with renal impairment, although caution should be exercised until more information is available regarding the safety of simeprevir in this population.

Acknowledgments Editorial support for the writing of this manuscript was provided by Melissa Yuan, MD, of MedErgy, and was funded by Janssen.

\section{Compliance with Ethical Standards}

Funding These studies were sponsored by Janssen.

Conflicts of interest S. O.-M., G. M., and I. W. are full-time employees of Janssen Research \& Development; M. B.-M., S. M., M. P., R. V., and A. S. are full-time employees of Janssen Infectious Diseases; and C. T. is a consultant at Janssen Infectious Diseases.

Ethical standards These studies were conducted in accordance with the principles of the Good Clinical Practice Guidelines and the Declaration of Helsinki. The final protocols were reviewed and approved by independent ethics committees, and all subjects provided written informed consent prior to study enrollment.

Open Access This article is distributed under the terms of the Creative Commons Attribution-NonCommercial 4.0 International License (http://creativecommons.org/licenses/by-nc/4.0/), which permits any noncommercial use, distribution, and reproduction in any medium, provided you give appropriate credit to the original author(s) and the source, provide a link to the Creative Commons license, and indicate if changes were made.

\section{References}

1. KDIGO clinical practice guidelines for the prevention, diagnosis, evaluation, and treatment of hepatitis $\mathrm{C}$ in chronic kidney disease. Kidney Int Suppl. 2008;(109):S1-99.

2. Lauer GM, Walker BD. Hepatitis $\mathrm{C}$ virus infection. N Engl J Med. 2001;345(1):41-52.

3. Fissell RB, Bragg-Gresham JL, Woods JD, et al. Patterns of hepatitis $\mathrm{C}$ prevalence and seroconversion in hemodialysis units from three continents: the DOPPS. Kidney Int. 2004;65(6):2335-42.

4. Huraib S, al-Rashed R, Aldrees A, et al. High prevalence of and risk factors for hepatitis $\mathrm{C}$ in haemodialysis patients in Saudi Arabia: a need for new dialysis strategies. Nephrol Dial Transplant. 1995;10(4):470-4.

5. Burra P, Rodriguez-Castro KI, Marchini F, et al. Hepatitis C virus infection in end-stage renal disease and kidney transplantation. Transpl Int. 2014;27(9):877-91.

6. Li CG, Ferrantelli A, Bono L, et al. Incidence of hepatitis $\mathrm{C}$ virus infection in patients with chronic kidney disease on conservative therapy. Int J Infect Dis. 2011;15(8):e514-6.

7. Latt N, Alachkar N, Gurakar A. Hepatitis C virus and its renal manifestations: a review and update. Gastroenterol Hepatol (NY). 2012;8(7):434-45.

8. Fabrizi F, Takkouche B, Lunghi G, et al. The impact of hepatitis $\mathrm{C}$ virus infection on survival in dialysis patients: meta-analysis of observational studies. J Viral Hepat. 2007;14(10):697-703.

9. Morales JM, Marcen R, Andres A, et al. Renal transplantation in patients with hepatitis $\mathrm{C}$ virus antibody: a long national experience. NDT Plus. 2010;3(suppl 2):ii41-6.

10. Latt NL, Araz F, Alachkar N, et al. Management of hepatitis C infection among patients with renal failure. Minerva Gastroenterol Dietol. 2015;61(1):39-49.

11. Rostaing L, Izopet J, Kamar N. Hepatitis C virus infection in nephrology patients. J Nephropathol. 2013;2(4):217-33.

12. Rebetol ${ }^{\circledR}$ (ribavirin USP) capsules [package insert]. Whitehouse Station: Merck \& Co., Inc.; 2013.

13. Pegasys ${ }^{\circledR}$ (peginterferon alfa-2a) injection for subcutaneous use [package insert]. South San Francisco: Genentech, Inc.; 2013.

14. Gupta SK, Pittenger AL, Swan SK, et al. Single-dose pharmacokinetics and safety of pegylated interferon-alpha2b in patients with chronic renal dysfunction. J Clin Pharmacol. 2002;42(10):1109-15.

15. Fabrizi F, Dixit V, Messa P, et al. Pegylated interferon monotherapy of chronic hepatitis $\mathrm{C}$ in dialysis patients: metaanalysis of clinical trials. J Med Virol. 2010;82(5):768-75.

16. Lindahl K, Schvarcz R, Bruchfeld A, et al. Evidence that plasma concentration rather than dose per kilogram body weight predicts ribavirin-induced anaemia. J Viral Hepat. 2004;11(1):84-7.

17. Copegus ${ }^{\circledR}$ (ribavirin) tablets [package insert]. South San Francisco: Genentech, Inc.; 2013.

18. de Kanter CT, Drenth JP, Arends JE, et al. Viral hepatitis C therapy: pharmacokinetic and pharmacodynamic considerations. Clin Pharmacokinet. 2014;53(5):409-27.

19. AASLD IDSA IAS-USA. Recommendations for testing, managing, and treating hepatitis C. 2014. Available from: http:// www.hcvguidelines.org. Accessed 20 Aug 2014.

20. Ghany MG, Nelson DR, Strader DB, et al. An update on treatment of genotype 1 chronic hepatitis $\mathrm{C}$ virus infection: 2011 practice guideline by the American Association for the Study of Liver Diseases. Hepatology. 2011;54(4):1433-44.

21. Rostaing L, Chatelut E, Payen JL, et al. Pharmacokinetics of alphaIFN-2b in chronic hepatitis $\mathrm{C}$ virus patients undergoing chronic hemodialysis or with normal renal function: clinical implications. J Am Soc Nephrol. 1998;9(12):2344-8. 
22. Liu CH, Huang CF, Liu CJ, et al. Pegylated interferon-alpha2a with or without low-dose ribavirin for treatment-naive patients with hepatitis $\mathrm{C}$ virus genotype 1 receiving hemodialysis: a randomized trial. Ann Intern Med. 2013;159(11):729-38.

23. SOVALDI ${ }^{\mathrm{TM}}$ (sofosbuvir) tablets [package insert]. Foster City: Gilead Sciences, Inc.; 2013.

24. Treitel M, Marbury T, Preston RA, et al. Single-dose pharmacokinetics of boceprevir in subjects with impaired hepatic or renal function. Clin Pharmacokinet. 2012;51(9):619-28.

25. Garg V, Kauffman RS, Beaumont M, et al. Telaprevir: pharmacokinetics and drug interactions. Antivir Ther. 2012;17(7): 1211-21.

26. Daklinza $30 \mathrm{mg}$ film-coated tablets [summary of product characteristics]. Uxbridge: Bristol-Myers Squibb Pharma EEIG; 2014.

27. Garimella T, Wang R, Luo W, et al. The effect of renal impairment on single-dose pharmacokinetics of daclatasvir, an HCV NS5A inhibitor. Presented at 15th international workshop on clinical pharmacology of HIV and hepatitis therapy; May 19-21, 2014; Washington, DC.

28. OLYSIO (simeprevir) capsules [package insert]. Titusville: Janssen Pharmaceuticals, Inc.; 2013.

29. European Medicines Agency. OLYSIO $150 \mathrm{mg}$ hard capsules (summary of product characteristics). 2014. Available from: http://www.ema.europa.eu/docs/en_GB/document_library/EPA R_-_Summary_for_the_public/human/002777/WC500167869. pdf. Accessed 30 June 2014.

30. Fried MW, Shiffman ML, Reddy KR, et al. Peginterferon alfa-2a plus ribavirin for chronic hepatitis $\mathrm{C}$ virus infection. $\mathrm{N}$ Engl $\mathrm{J}$ Med. 2002;347(13):975-82.

31. Forns X, Lawitz E, Zeuzem S, et al. Simeprevir with peginterferon and ribavirin leads to high rates of SVR in patients with HCV genotype 1 who relapsed after previous therapy: a phase 3 trial. Gastroenterology. 2014;146(7):1669-79.

32. Zeuzem S, Berg T, Gane E, et al. Simeprevir increases rate of sustained virologic response among treatment-experienced patients with HCV genotype-1 infection: a phase IIb trial. Gastroenterology. 2014;146(2):430-41.

33. Manns M, Marcellin P, Poordad F, et al. Simeprevir with pegylated interferon alfa $2 \mathrm{a}$ or $2 \mathrm{~b}$ plus ribavirin in treatment-naive patients with chronic hepatitis $\mathrm{C}$ virus genotype 1 infection (QUEST-2): a randomised, double-blind, placebo-controlled phase 3 trial. Lancet. 2014;384(9941):414-26.

34. Jacobson IM, Dore GJ, Foster GR, et al. Simeprevir with pegylated interferon alfa 2a plus ribavirin in treatment-naive patients with chronic hepatitis $\mathrm{C}$ virus genotype 1 infection (QUEST-1): a phase 3, randomised, double-blind, placebo-controlled trial. Lancet. 2014;384(9941):403-13.

35. Lawitz E, Sulkowski MS, Ghalib R, et al. Simeprevir plus sofosbuvir, with or without ribavirin, to treat chronic infection with hepatitis $\mathrm{C}$ virus genotype 1 in non-responders to pegylated interferon and ribavirin and treatment-naive patients: the COSMOS randomised study. Lancet. 2014;384(9956):1756-65.

36. Dieterich D, Rockstroh J, Orkin C, et al. Simeprevir (TMC435) plus pegIFN/ribavirin in $\mathrm{HCV}$ genotype-1/HIV coinfection (Study C212). Oral presentation at conference on retroviruses and opportunistic infections (CROI); March 3-6, 2014; Boston, Massachusetts.

37. Moreno C, Hezode C, Marcellin P, et al. Once-daily simeprevir (TMC435) with peginterferon/ribavirin in treatment-naïve or treatment-experienced chronic HCV genotype 4-infected patients: final results of a phase III trial. Poster presented at 49th annual meeting of the European Association for the Study of the Liver (EASL); April 9-13, 2014; London, UK.

38. Lin TI, Lenz O, Fanning G, et al. In vitro activity and preclinical profile of TMC435350, a potent hepatitis $\mathrm{C}$ virus protease inhibitor. Antimicrob Agents Chemother. 2009;53(4):1377-85.

39. Huisman MT, Snoeys J, Monbaliu J, et al. In vitro studies investigating the mechanism of interaction between TMC435 and hepatic transporters. Poster presented at 61 st annual meeting of the American Association for the Study of Liver Disease (AASLD); October 29-November 2, 2010; San Francisco, CA.

40. Dreisbach AW, Lertora JJ. The effect of chronic renal failure on drug metabolism and transport. Expert Opin Drug Metab Toxicol. 2008;4(8):1065-74.

41. Janssen. Antiviral Drugs Advisory Committee meeting. Briefing document: simeprevir (TMC435). Treatment of patients with chronic hepatitis C. NDA 205123. 2013.

42. Fenoglide. Fenoglide (fenofibrate) tablets, for oral use [package insert]. 1993. San Diego: Santarus Inc; 2013.

43. Victrelis ${ }^{\circledR}$ (boceprevir) capsules [package insert]. Whitehouse Station: Merck \& Co., Inc.; 2014.

44. Incivek ${ }^{\circledR}$ (telaprevir) tablets [package insert]. Cambridge: Vertex Pharmaceuticals, Inc.; 2013.

45. van Heeswijk R, Vandevoorde A, Boogaerts G, et al. The effect of severe renal impairment on the pharmacokinetics of the investigational $\mathrm{HCV}$ protease inhibitor telaprevir. J Hepatol. 2014;54(suppl 1):S492 (abstract 1245).

46. Gupta SK, Kantesaria B, Glue P. Pharmacokinetics and safety of single-dose ribavirin in patients with chronic renal impairment. Drug Discov Ther. 2013;7(4):158-63. 